\title{
BRAIN DEATH AND ORGAN DONATION: A COMPARISON OF THREE INFLUENTIAL GROUPS OF MUSLIM PROFESSIONALS
}

\author{
Makmor $T^{1}$, Roza Hazli $Z^{2}$, Khaled T³ , NurulHuda MS ${ }^{2}$, Nawi $A^{1}$, Wan Ahmad Hafiz WMA ${ }^{4}$, Mohd Yakub @ Zulkifli MY5 \\ 1 Department of Administrative Studies and Politics, Faculty of Economics and Administration, University of Malaya, \\ Kuala Lumpur \\ 2 Department of Economics, Faculty of Economics and Administration, University of Malaya, Kuala Lumpur \\ 3 Institute of Research Management and Monitoring, University of Malaya, Kuala Lumpur \\ 4 Department of Medicine, Faculty of Medicine, University of Malaya, Kuala Lumpur \\ 5 Department of Al-Quran and Al-Hadith, Academy of Islamic Studies, University of Malaya, Kuala Lumpur
}

\section{Correspondence:}

Makmor Tumin, PhD, Associate Professor,

Department of Administrative Studies and Politics Faculty of Economics and Administration,

University of Malaya, 50603 Kuala Lumpur, Malaysia.

E-mail:makmor@um.edu.my

\begin{abstract}
Organ transplantation is a new treatment for end-stage organ failure. However, the total number of transplants performed in Malaysia in 2012 was only 94. Rates of deceased and living donors in Malaysia for 2012 were chronically low ( 0.55 and 1.87 per million population, respectively). A sample of 350 respondents in mosques, hospitals, and universities in various places in the Klang Valley, Kelantan and Pahang were collected between October and December 2013 to investigate the level of knowledge of health care professionals (HCPs), religious leaders (RLS), and academics (ACAs) and their stand on two issues on brain death. The result on the first issue (procuring organs from brain dead donors for transplantation) revealed that $52.8 \%, 23.7 \%$, and $23.4 \%$ of HCPs, RLs, and ACAs, respectively, were in support of it; $30.2 \%, 31.8 \%$, and $45.2 \%$ were uncertain about it; and $17 \%$, 44.5\%, and 31.5\% were against it. On the second issue (terminating the life support machine of a brain dead person), $60.4 \%, 35.7 \%$, and $25 \%$ of HCPs, RLs, and ACAs, respectively, were in support of it; $26.4 \%, 36.4 \%$, and $38.7 \%$ were uncertain about it; and $13.2 \%, 27.7 \%$, and $36.3 \%$ were against it. The lack of knowledge on Islam brain death-related issues should be addressed by educational efforts targeting these three groups of professionals. Special emphasis should be paid to educating RLs as they can channel their knowledge and perception to the other groups and to the Muslim public.
\end{abstract}

Keywords: brain death, knowledge, Malaysia, Muslim, organ donation

\section{Introduction}

Rapid medical progress has introduced organ transplantation as a new treatment for end-stage organ failure. The success of this new treatment depends vitally on the availability of donated organs. However, many countries around the globe have faced a severe organ shortfall, impeding the treatment of thousands of patients needing an organ transplant. In Malaysia, the number of dialysis patients in 2012 was 28,590 , with about half registered on the waiting list for a renal transplantation; however, the total number of transplants performed in that year was only $94(1,2)$. The major cause of this discrepancy was that rates of deceased and living donors in Malaysia for 2012 were chronically low (0.55 and 1.87 per million population, respectively) compared with other countries in the developed and developing world, such as Spain $(35.12,8.59)$, the United
Kingdom (20.7, 17.8), Iran (8.7, 20), Turkey (5.0, 46.6), Kuwait $(3.7,16.7)$, and Saudi Arabia $(2.5,24.7)(3)$.

To address the dilemma of organ shortage, many studies have investigated factors affecting organ donation. Most such studies emphasise the importance of knowledge on organ donation and transplantation in determining willingness to donate organs (4-10). On the other hand, many authors have also identified the role of religion in guiding people's viewpoints and attitude toward organ donation (7,11-1Generally, people become more willing to donate when they know that religious leaders (RLs) support organ donation (15). Muslim scholars or RLs are responsible for making Islamic rulings about contemporary issues and advising the Muslim public on those issues. The role of RLS is thus vital in driving up donation rates (15-18). In Turkey, a study showed that about $50 \%$ of Muslim RLs had been 
consulted on organ donation issues (11). In Malaysia, 84\% of Muslim health care professionals (HCPs) admit that RLs play an imperative role in educating the public on organ donation (19). Another study in Malaysia has shown that RLs are the second most preferred promoter of organ donation (20).

The knowledge and attitude of HCPs toward organ donation and brain death is of great importance, since they are in direct contact with patients and their families, who are potential organ donors. In this context, many studies have found a relationship between training HCPS on organ donation and organ donation rates $(21,22)$. A study in Turkey concluded that a lack of knowledge on organ donation has negative effects on $\mathrm{HCPs}^{\prime}$ views toward organ donation. Another study found that $28.7 \%$ of Turkish HCPs do not donate their organs due to their Islamic religious beliefs (8). A recent study in Malaysia showed that willingness to donate organs is lowest among Muslim HCPs (37.3\%) compared with those of other religions. The study suggested that the misconception among HCPs about brain death is a significant reason impeding HCPs' abilities to identify organ donors, and, thus, undermining donation rates (19).

Academics (ACAs) are presumed to have a great deal of influence through either teaching in universities or conducting research and proposing policies that shape the destiny of their communities. Unfortunately, no study has thus far been conducted to explore ACAs' viewpoints and attitude toward organ donation and brain death. Moreover, to the best of our knowledge, no study has been conducted on Malaysian RLs' perception and knowledge on the issue of organ donation and brain death or on the permissibility of procuring organs from a brain dead donor. This is imperative given the knowledge and perception of Muslim HCPs and ACAs, and is thus the aim of this study.

\section{Methods}

A survey was conducted in different areas for different sample groups. RLs' sample was based on 82 mosques in the Klang Valley. HCPs' sample was based on 3 hospitals; University Malaya Medical Centre (33), Hospital Raja Perempuan Zainab II (10), and Hospital Tengku Ampuan Afzan (10). ACAs' sample was collected from 3 universities in the Klang Valley; University of Malaya, Universiti Sains Islam Malaysia (USIM), and Universiti Teknologi MARA (UiTM) Shah Alam. The study was approved by the University of Malaya Research Ethics Committee (Reference Number: UM.TNC2/RC/H\&E/UMREC).

Enumerators were trained to approach HCPs, RLs, and ACAs in their respective locations and obtained respondents' verbal consent before proceeding with the survey. Selfadministered and pilot-tested questionnaires were handed over to respondents. In the survey, $53 \mathrm{HCPs}, 173 \mathrm{RLs}$, and 124 ACAs, totalling 350 respondents, participated; all respondents were Muslims.

An RL in this survey is understood as (i) an individual with an Islamic educational background and/or (ii) an active member of a local mosque's committee. Academics who have an Islamic background and are also a part of the mosque committee are grouped under RLs in this study.

After completing the demographic section of the questionnaire, respondents were asked to answer the question: "Are you willing to become a donor upon death?" They were presented with two options, "Yes" or "No". This question is important to examine their overall attitude toward being deceased donors. Next, to examine their level of knowledge, the following seven questions of common knowledge were presented to them with the same "Yes" or "No" options:

1. Healthy individuals can lead a normal life with one kidney.

2. Organs from deceased donors can be retrieved even without the donor's family's consent.

3. A person is actually dead if his/her brain has stopped functioning, even though his/her heart is still beating with the aid of a machine.

4. Living donors can lead a normal life without medication.

5. An organ donated by a Malay, Chinese, Indian, or a person from other ethnic groups would only be transplanted to a patient of the same ethnicity.

6. Registering with a medical officer is the only way to become a deceased donor.

7. Fatwa (Islamic ruling) in Malaysia allows organ donation.

Respondents' level of knowledge was divided into three groups based on their correct answers: poor, 2 and below; moderate, 3 to 4; and good, 5 to 7 . Finally, their views on two issues related to brain death were recorded. The issues were "Removing organs from brain dead patients for transplant purposes is permissible in Islam" and "Switching off the mechanical ventilator for brain dead patients is permissible in Islam". A five-point Likert scale was used to determine the score for each item (strongly disagree, disagree, not sure, agree, strongly agree). Respondents' attitude were divided into 3 groups; support (respondents that strongly agree and agree), uncertain (respondents that are not sure), and against (respondents that strongly disagree and disagree). The questionnaires were distributed in Bahasa Melayu.

\section{Results}

The results of the surveys indicate that of the 350 respondents, 220 (62.9\%) are willing donors. From these numbers, $16.4 \%$ willing donors are HCPs, $49.5 \%$ RLs, and $34.1 \%$ ACAs.

Table 1 presents respondents' demographic and socioeconomic characteristics

The overall background of the three group of respondents is as follows; Out of 350 respondents, 237 (67.7\%) were male. $28.3 \%$ of the respondents were aged 35 years and below, $54.3 \%$ were aged 36 to 50 years, while the remaining 
Table 1: Respondents' Background

\begin{tabular}{|c|c|c|c|c|}
\hline Respondents' Background & $\begin{array}{l}\text { HCP* } \\
(n=53)\end{array}$ & $\begin{array}{c}\mathrm{RL} * * \\
(\mathrm{n}=173)\end{array}$ & $\begin{array}{l}\text { Aca*** } \\
(n=124)\end{array}$ & $\begin{array}{c}\text { Total } \\
(n=350)\end{array}$ \\
\hline \multicolumn{5}{|c|}{ Gender } \\
\hline Male & 20 & 130 & 87 & 237 \\
\hline Female & 33 & 43 & 37 & 113 \\
\hline \multicolumn{5}{|c|}{ Age } \\
\hline 35 years and below & 28 & 44 & 27 & 99 \\
\hline 36 to 50 years old & 24 & 91 & 75 & 190 \\
\hline 51 years old and above & 1 & 38 & 22 & 61 \\
\hline \multicolumn{5}{|c|}{ Income } \\
\hline RM 2,000 and below & 0 & 79 & 0 & 79 \\
\hline RM 2,001 to RM 4,000 & 0 & 67 & 0 & 67 \\
\hline RM 4,001 to RM 6,000 & 15 & 18 & 71 & 101 \\
\hline RM 6,001 to RM 8,000 & 12 & 4 & 17 & 33 \\
\hline RM 8,001 to RM 10,000 & 6 & 4 & 24 & 34 \\
\hline RM 10,00 and above & 20 & 1 & 12 & 33 \\
\hline \multicolumn{5}{|c|}{ Education Background } \\
\hline Conventional education & 48 & 115 & 124 & 287 \\
\hline Islamic education & 5 & 58 & 0 & 63 \\
\hline \multicolumn{5}{|c|}{ Highest Education } \\
\hline School and Undergraduate Level & 0 & 166 & 0 & 168 \\
\hline Postgraduate level & 53 & 7 & 124 & 181 \\
\hline
\end{tabular}

Field of knowledge (respondents with higher education only)

\begin{tabular}{lcccc} 
Medical science & 53 & 0 & 0 & 53 \\
Non-medical science & 0 & 3 & 17 & 20 \\
Social science/Islamic studies & 0 & 18 & 107 & 125 \\
\hline
\end{tabular}

Mosque committee

Yes

3

1550

37

195

*HCP - Health Care Professionals

** RL - Religious Leaders

***Aca - Academicians 
Table 2: Respondents' Level of Knowledge (general information) on Organ Donation and Transplantation

\begin{tabular}{lcccccccc}
\hline Level & $\mathrm{HCP} *$ & $\%$ & $\mathrm{RL} * *$ & $\%$ & Aca*** & $\%$ & Total & $\%$ \\
& $(\mathrm{n}=53)$ & & $(\mathrm{n}=173)$ & & $(\mathrm{n}=124)$ & & \multicolumn{2}{c}{$(\mathrm{n}=350)$} \\
\hline Poor & 2 & 3.8 & 50 & 28.9 & 21 & 16.9 & 73 & 20.9 \\
Moderate & 28 & 52.8 & 103 & 59.5 & 79 & 63.7 & 210 & 60.0 \\
Good & 23 & 43.4 & 20 & 11.6 & 24 & 19.4 & 67 & 19.1 \\
\hline
\end{tabular}

*HCP - Health Care Professionals

$* * \mathrm{RL}$ - Religious Leaders

$* * *$ Aca - Academicians

Table 3: Respondents' Perspective on Brain Death and Organ Donation from an Islamic Standpoint

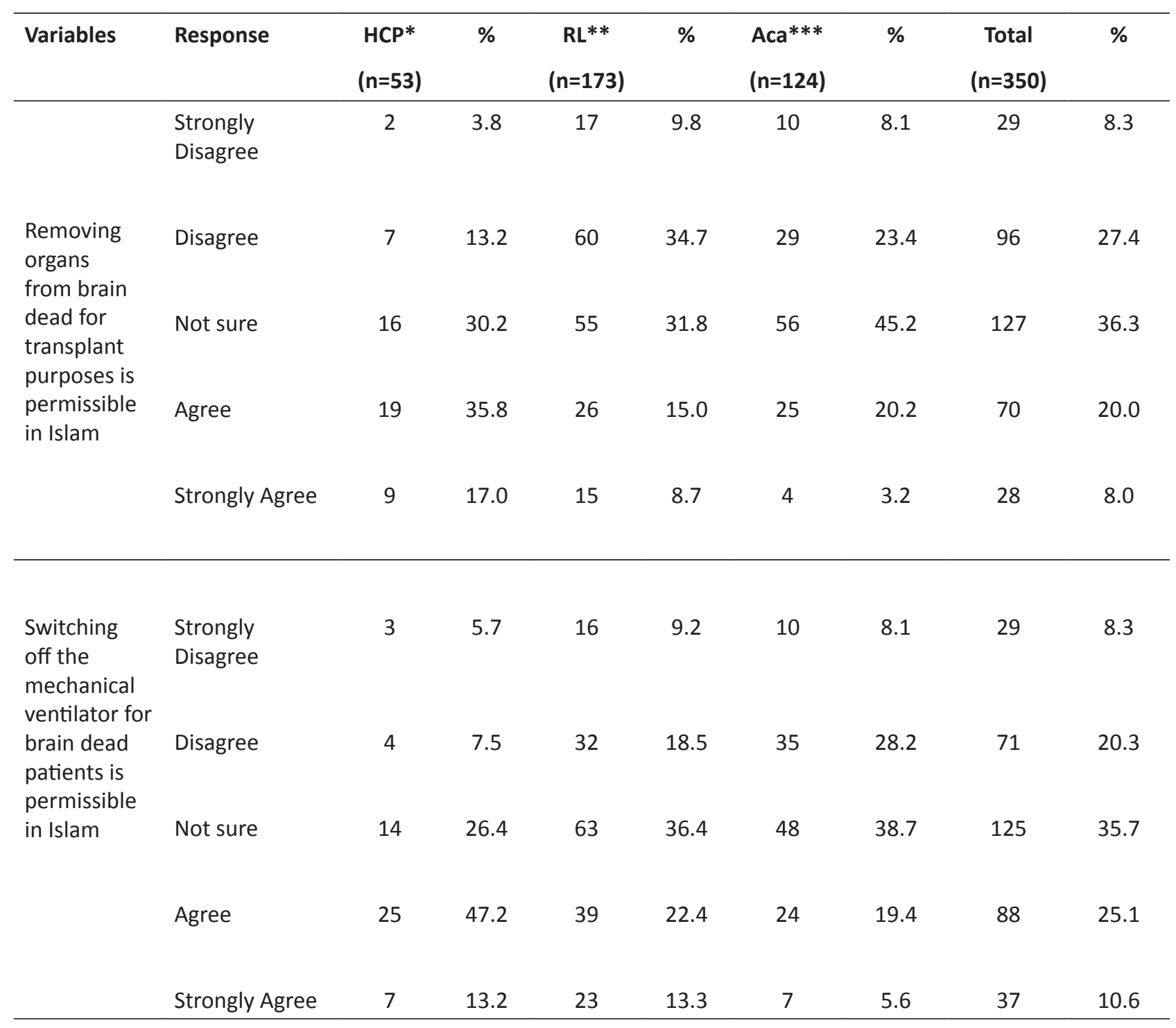

*HCP - Health Care Professionals

$* * \mathrm{RL}$ - Religious Leaders

$* * *$ Aca - Academicians 
$17.4 \%$ were aged 51 years and above. Based on income, 79 (22.6\%) had incomes of RM2000 and below, 67 (19.1\%) had incomes of RM2001-RM4000, 101 (28.9\%) had incomes of RM4001-RM6000, 33 (9.4\%) had incomes of RM6001RM8000, 34 (9.7\%) had incomes of RM8001-RM10000; and finally, 33 (9.4\%) had incomes above RM10000. 287 (82\%) of the respondents had conventional education while the remaining $63(18 \%)$ went through Islamic education. Based on highest education, 168 (48\%) reached school and undergraduate level, while the remaining 181 (52\%) reached postgraduate level. 53 (15.1\%) of respondents were medical science based, 20 (5.7\%) were non-medical science based, while 125 (35.7\%) went through Islamic studies and social science studies. The remaining $43.5 \%$ of the respondents did not have higher education.

Table 2 indicates that RLs' level of knowledge on organ donation and transplantation is the lowest compared with ACAs, while the level of knowledge of HCPs is the highest. Only $11.6 \%$ of RLs have good knowledge on organ donation compared with $19.4 \%$ of ACAs and $43.4 \%$ of HCPs.

Table 3 indicates that more than one third of respondents are unsure that "Switching off the mechanical ventilator for brain dead patients is permissible in Islam". ACAs were the least knowledgeable on this issue, while HCPs were the most knowledgeable. In other words, the majority of HCPs $(60.4 \%)$ support that brain death criteria comply with Islamic teachings on death, while only $35.7 \%$ of RLs and $25 \%$ of ACAs support this notion.

The three groups' support for the second issue related to brain death is slightly lower compared with the first. Only $52.8 \%, 23.7 \%$, and $23.4 \%$ of HCPs, RLs, and ACAs, respectively, side with removing organs from brain dead patients for transplant purposes. On the same matter, a sizable portion of HCPs (30.2\%), RLs (31.8\%), and ACAs (45.2\%) are uncertain, as shown in Table 3.

\section{Discussion and Conclusion}

Malaysia is a multi-ethnic country with three chief ethnic groups: Malay (50.1\%), Chinese (22.6\%), and Indian (6.7\%). Four main religions prevail in the country: Islam (61.3\%), Buddhism (19.8\%), Christianity (9.2\%), and Hinduism (6.3\%) (23). Becoming an organ donor in Malaysia requires the willing donor to register his/her wish officially. Registration can be performed easily online through a user-friendly website (http://www.dermaorgan.gov.my)(24).

Generally, most religions permit organ donation and transplantation (12). As for Islam, the majority of Muslim scholars or RLs permit organ donation as a form of charity $(16,25-28)$. In Malaysia, organ donation and transplantation have been recognised and permitted by the National Fatwa Council since 1970. The official Islamic verdict in Malaysia also allows cross-religion and cross-ethnic organ donation and transplantation (24).Organs can be procured from a cadaver or a brain dead donor; however, in most countries, most organs for transplantation are sourced from brain dead donors owing to viability constraints(29).
Muslim scholars have been in controversial deliberations about the definition of death, which is a vital factor to determine donated organs. The traditional definition of death in Islam is "the departure of the soul from the body". Derived from the primary source of Islamic jurisprudence - Quran and Hadith - this definition is vague and does not provide a clear illustration of the signs of soul departure (30).

Medical advancement has led to a new definition of death, "brain death", introduced in 1968 by a group of scholars from Harvard Medical School. In their words, brain death is an "irreversible cessation of function of the entire brain" (31). Accordingly, Muslim scholars have been urged to determine whether the new definition of death complies with Islamic teachings. However, consensus on the issue of brain death among Muslim scholars remains lacking. Nevertheless, the majority of Islamic rulings and the verdict of important bodies in the Muslim world, such as the Islamic Fiqh Academy (1988) and Islamic Organization for Medical Sciences (1985), have approved brain death as the modern medical sign of death $(32,33)$.

Earlier studies found that the lack of information on organ donation and transplantation caused the Malaysian public to be unwilling to donate $(6,34)$. Although knowledge on organ donation should not be low among people with higher levels of education, surprisingly, this study shows that the three professional groups investigated in this work - HCPs, RLs, and ACAs - lack adequate knowledge on the basic issues of organ donation and transplantation, with RLs showing the worst level of understanding.

The absence of adequate knowledge among the studied groups is extended - by the findings of this study - to cover the permissibility of terminating the life support machines of brain dead patients, and, hence, the permissibility of procuring organs from brain dead persons for transplantation purposes.

The lack of knowledge is rather chronic among RLs, although they are expected to be more exposed to Islamic contemporary fatwas in the country. This finding indicates that the new definition of death introduced in 1968 by Harvard medical experts and approved in 1992 by Muslim officials has not been promoted properly among the three groups in this study, especially RLs who are expected to play a vital role in channelling information on organ donation to Malaysian Muslim communities(19,20).

The role of HCPs is very significant in organ donation. HCPs are responsible for declaring the death of a patient, contacting an organ donation coordinator, and approaching families of prospective donors to obtain their consent to procure his/her organs $(19,21)$. Thus, HCPs are undoubtedly a key determinant of organ donation rates. Ethical concerns among HCPs are determined within their cultural frames besides their theological beliefs. The theological concerns of HCPs may lead to the acceptance or rejection of organ donation (8). Therefore, a lack of knowledge among HCPs on organ donation and brain death - connected 
with their theological beliefs - means the severe failure to procure donated organs for transplantation $(21,22)$. Thus, the relatively low level of knowledge among HCPs shown in this study is a serious problem that needs to be addressed urgently to increase awareness on the issue of organ donation.

The inclusion of ACAs in this study provides us with two important elements. The first is to gauge their views on the issues searched, as ACAs are deemed to influence the nation's future. The second is to provide an unbiased benchmark when comparing RLs and HCPs, since the topic investigated is medical-religious-oriented. As a result, this study reveals that ACAs exhibit the least acceptance and highest uncertainty about issues pertaining to brain death among the three groups. The comparison presented herein shows a wide gap between HCPs and RLs in terms of knowledge on the Islamic view of brain death issues. For instance, $52.8 \%$ of HCPs agree that removing organs from brain dead donors is permissible in Islam compared with $23.7 \%$ of RLS and $23.4 \%$ of ACAs.

The ambiguity and misconception among Islamic perspectives on brain death urge educational initiatives aiming to increase awareness of the Islamic permissibility of announcing brain dead patients as deceased and procuring their organs. These would enhance the number of approached donors and thus the number of organ transplantations in the country.

The need for educational efforts on brain death should intensively target RLs for three reasons. The first is that their level of knowledge on Islam brain death matters is very low. The second is that RLs can influence the public's perception of organ donation more than other professional groups. The third is that RLs can serve as a reference of knowledge for HCPs and ACAs when they seek information on the Islamic perspective of brain death. Such an argument is supported by the recent findings that show that about $84 \%$ of Malaysian Muslim HCPs stress the important role of RLs in raising the awareness of and promoting organ donation(19).

This study has some limitations. It only covered the Klang Valley, and 2 hospitals in Kuantan, Pahang and Kota Bharu, Kelantan; thus, generalising the findings may suffer some bias. However, we argue that the demographic and urban characteristics of these areas mirror the components of the Malaysian Muslim community, by and large. Another limitation is that the number of HCPs is much lower than the participants from other groups. Nevertheless, we believe that the samples roughly portray the relative formation of the three professions in the country.

Our analysis of 53 HCPs, 173 RLs, and 124 ACAs reveals that they lack adequate knowledge on the Islamic stance on brain death and the permissibility of procuring organs from brain dead donors. This lack of knowledge may have been undermining organ donation and transplantation activities in Malaysia, as brain dead donors are the ultimate source of organs. An educational strategy should be taken into account to address this deficit in information. We suggest that RLs need this education the most as key players in determining organ donation status in the Islamic community.

\section{Limitations and Future Studies}

This study was based on participants from 3 medical centres and 3 universities. The views of HCPs and ACAs in other institutions might be slightly different. In addition, the study did not investigate within-group differences because it initially aimed to compare influential groups (HCPs, RLs, and ACAs) without within-group settings. Future studies may cover a larger number of medical and academic institutions and may include within-group analysis.

\section{Acknowledgement}

The authors wish to thank the University of Malaya for funding the research under the Research Grant Scheme (Project No.: RG490-13HTM).

\section{References}

1. National Transplant Resource Centre, Ministry of Health Malaysia. http://www.dermaorgan.gov.my/ en/statistics. Accessed Dec 31, 2014.

2. Goh BL, Ong LM, Lim YN, (eds.) 21th Report of the Malaysian Dialysis and Transplant Registry 2013. Kuala Lumpur: National Renal Registry, Malaysian Society of Nephrology, 2014.

3. International registry of organ donation and transplantation (IRODaT). http://www.irodat.org. Accessed Oct 28, 2014.

4. Rosenblum AM, Horvat LD, Siminoff $L$ a., Prakash V, Beitel J, Garg AX. The authority of next-of-kin in explicit and presumed consent systems for deceased organ donation: An analysis of 54 nations. Nephrol Dial Transplant 2012; 27:2533-2546.

5. Irving MJ, Tong A, Jan S, Cass A, Rose J, Chadban S, et al. Factors that influence the decision to be an organ donor: A systematic review of the qualitative literature. Nephrol Dial Transplant 2012; 27:25262533.

6. Tumin M, Noh A, Jajri I, Chong CS, Manikam R, Abdullah N. Factors that hinder organ donation: Religio-cultural or lack of information and trust. Exp Clin Transplant 2013; 11:207-210.

7. Topbaş M, Çan G, Çan M a., Özgün Ş. Outmoded attitudes toward organ donation among Turkish health care professionals. Transplant Proc 2005; 37:1998-2000.

8. Tokalak I, Başaran O, Emiroğlu R, Kut A, Karakayali H, Bilgin $\mathrm{N}$, et al. Health care professionals' knowledge of procedural issues in transplantation: the need for continuing education programs. Transplant Proc 2015; 36(1):14-16.

9. Weaver M, Spigner C, Pineda M, Rabun KG, Allen MD. Knowledge and opinions about organ donation among urban high school students: pilot test of a health education program. Clin Transplant 2000; 14(4 Pt 1):292-303. 
10. Akgün HS, Bilgin N, Tokalak I, Kut A, Haberal M. Organ donation: a cross-sectional survey of the knowledge and personal views of Turkish health care professionals. Transplant Proc 2003; 35(4):12731275.

11. Uskun E, Ozturk M. Attitudes of Islamic religious officials toward organ transplant and donation. Clin Transplant 2013; 27:37-41.

12. Oliver M, Woywodt A, Ahmed A, Saif I. Organ donation, transplantation and religion. Nephrol Dial Transplant 2011; 26:437-44.

13. Guy BS, Aldridge A. Marketing organ donation around the globe. Mark Health Serv 2001; 21(4):30-35.

14. Bruzzone P. Religious aspects of organ transplantation. Transplant Proc 2008; 40:1064-1067.

15. Skowronski JJ. On the psychology of organ donation: Attitudinal and situational factors related to the willingness to be an organ donor. Basic App/ Soc Psych 1997; 19(4):427-456.

16. Ilyas $M$, Alam M, Ahmad H. The Islamic perspective of organ donation in Pakistan. Saudi J Kidney Dis Transpl 2009; 20(1):154-156.

17. Rumsey S, Hurford DP, Cole a. K. Influence of knowledge and religiousness on attitudes toward organ donation. Transplant Proc 2003; 35:28452850.

18. Davis C, Randhawa G. The influence of religion on organ donation and transplantation among the Black Caribbean and Black African population--a pilot study in the United Kingdom. Ethn Dis 2006; 16(1):281-285.

19. Abidin ZLZ, Ming WT, Loch A, Hilmi I, Hautmann O. Are health professionals responsible for the shortage of organs from deceased donors in Malaysia? Transpl Int 2013; 26:187-194.

20. Tumin M, Noriza R, Ariffin R, Satar NM. Organ donation campaigns : Perspective of dialysis patient's family members. Iran J Public Health 2014; 43(7):926-935.

21. Gaber AO, Hall G, Phillips DC, Tolley EA, Britt LG. Survey of attitudes of health care professionals toward organ donation. Transplant Proc 1990; 22(2):313-315.

22. Light JA, Kowalski AE, Ritchie WO, Gage F, Sasaki TM, Aquino A, et al. New profile of cadaveric donors: what are the kidney donor limits? Transplant Proc 1996; 28(1):17-20.

23. Department of Statistics Malaysia. 2010. Population distribution and basic demographic characteristics. http://www.statistics.gov.my/portal/download_ Population/files/census2010/Taburan_Penduduk_ dan_Ciri-ciri_Asas_Demografi.pdf. Accessed Mar 24, 2015.

24. Ministry of Health Malaysia. Organ transplantation from the Islamic perspective. Putrajaya: Ministry of Health Malaysia, 2011.

25. Hassaballah AM. Mini symposium. Definition of death, organ donation and interruption of treatment of Islam. Nephrol Dial Transplant 1996; 11(6):964965.

26. Albar M. Organ transplantation: a Sunni Islamic perspective. Saudi J Kidney Dis Transpl 2012; 23(4):817-822.

27. Al-Qaradawi Y. Alsharia'ah wa-alhayat: The Islamic jurisprudence perspective on organ donation (Arabic). http://aljazeera.net/programs/pages/14c54fdcb60c-41fa-bb6e-d167f2232eab. Accessed Apr 28, 2014.

28. Van Den Branden S, Broeckaert B. The ongoing charity of organ donation. Contemporary english sunni fatwas on organ donation and blood transfusion. Bioethics 2011; 25(3):167-175.

29. Haque OS. Brain death and its entanglements. A redefinition of personhood for Islamic ethics. J Relig Ethics 2008; 36(1):13-36.

30. Sarhill N, LeGrand S, Islambouli R, Davis MP, Walsh D. The terminally ill Muslim: Death and dying from the Muslim perspective. Am J Hosp Palliat Care 2011; 18(4):251-255.

31. A definition of irreversible coma. Report of the Ad Hoc Committee of the Harvard Medical School to examine the definition of brain death. JAMA1984; 252(5):677-679.

32. Padela Al, Arozullah A, Moosa E. Brain death in Islamic ethico-legal deliberation: Challenges for applied Islamic bioethics. Bioethics 2013; 27(3):132-139.

33. Miller AC, Ziad-Miller A, Elamin EM. Brain death and Islam: The interface of religion, culture, history, law, and modern medicine. Chest 2014; 146(4):10921101.

34. Tumin M, Noh A, Mohd Satar N, Chin-Sieng C, SooKun L, Abdullah N, et al. Organ donation in Muslim countries: the case of Malaysia. Ann Transplant 2013; 18:671-676. 